\title{
Analysis of Industrial Response Mechanism of COVID-19 Risk Impact
}

\author{
Run Chai ${ }^{1}$, Xiaolin $\mathrm{Li}^{1{ }^{1 *}}$ \\ ${ }^{I}$ Central Financial and Economic University, School of Insurance \\ *Xiaolin Li. Email:1ix1@cufe. edu.cn
}

\begin{abstract}
In January 2020, COVID-19 suddenly broke out, then Wuhan province had to be isolated and people had to observe home quarantine in China. The epidemic led to instantaneous closure of the business catering, entertainment, tourism and other service industries. Most of the traffic was interrupted, enterprises were shut down, and economic activities almost stopped. This paper uses grey prediction and event analysis to establish a model and finds that, (1) in the short term, the response sequence of among related industries is service industry, industrial and commercial enterprises, and then agriculture. (2) the general industry will tend to balance for a long time, and the impact is not big. (3) the epidemic exposed the weakness of emergency management and rapid response mechanism in megacities. Therefore, the government should initiated emergency response, and use the strategic resources reserve to ensure that economic and social resources are tilted to the normal production and operation of the epidemic related industries. Through fiscal and monetary counter-cyclical regulation, the government supports the classified management of various industries and the gradual resumption of production, supports the replacement and upgrading of high-tech industries over traditional industries, and reduces the impact of the overall economy caused by industrial emergency imbalance.
\end{abstract}

Keywords: COVID-19 risk impact, Industry response, Influence mechanism

\section{新冠肺炎疫情风险冲击的产业响应机理分析}

\author{
柴 润 $^{1}$, 李晓林 ${ }^{1, *}$
}

1 中央财经大学保险学院
*李晓林, 电子邮稓: lixl@cufe.edu.cn

\section{摘要}

2020 年 1 月, 新冠肺炎突然爆发, 武汉紧急封城, 全国居家隔离, 疫情导致商贸餐饮、文化娱乐、度假旅 游等服务业几乎瞬间停业, 大部分交通中断和企业停工停产, 经济活动几乎停止。本文运用灰色预测和事件 分析法建立模型分析发现，（1）短期各产业间联动的响应顺序为先服务业、后工商企业、再农业。(2) 长 期产业运行将趋于平衡, 影响不大。（3）疫情还暴露了超大城市应急管理与快速响应机制的薄弱。因此, 政府需要启动应急响应, 保障经济社会资源向疫情相关行业的正常生产运营倾斜; 通过财政与货币政策逆 周期调控, 支持各行业分类管理和逐步开工复产, 支持高新技术产业对传统产业的替代升级, 减轻疫情导 致产业应急失衡对整体经济的影响。

关键词: 新冠疫情风险冲击; 产业响应; 影响机理

\section{1. 引言}

2020 年 1 月, 新冠病毒肺炎 (COVID-19) 在湖 北武汉出现，随后逐步扩散，2020 年 1 月 23 日武 汉宣布 “封城”，随后中国 30 个省市启动突发公共 事件一级响应并颁布相应政策和配套措施，全国居 家隔离，暂停部分公共交通，关闭娱乐场所，禁止
公共聚会等。1月 31 日, 世界卫生组织（WHO）宣 布此次疫情被列为 “国际关注的突发卫生事件” (PHEIC)。截止 4 月 7 日, 中国疫情累计确诊病例 超过八万，远远超过了 2003 年非典感染数量。

一直以来, 大规模传染病都是人类社会发展中 不可忽视且无法预测的潜在敌人。“雅典大瘟疫”、 
“黑死病”、“西班牙大流感”所带来的影响都远超 过战争对人类社会的打击。步入 21 世纪后, 随着 产业链全球化的趋势逐步增强，各国经济之间的连 通性使得传染病对于整个人类社会都存在着潜在 威胁。大规模突发疫情带来劳动力等重要生产要素 的缺失, 以及疫情直接医疗成本以及非医疗成本, 通过产业链之间传递带来整体经济社会系统性的 损失冲击。因此, 对重大疫情的经济影响研究是必 不可少的。

\section{2. 文献综述}

近二十年来，全球爆发的各类传染病事件所造 成经济影响是不可忽视的, 大部分的传染病事件带 来的经济影响持续了整个季度，造成经济增长下滑 甚至出现负增长, 各个疫情严重国家所处经济发展 阶段以及整体经济环境的不同, 影响效应的持续时 间均呈现不一致性。

对比自然灾害与金融危机而言，突发疫情作为 有危害性的公共卫生事件对经济造成的影响一般 认为是主要是外部性的冲击（吕炜等, $2003^{[1]}$; 张 文斗等, $2014^{[2]}$ ), 其解决方式的独特性 (如 SARS 依 靠隔离使得病毒自行消亡) 使我们意识到可以用经 验来更好地化解这类危机。在微观层面上, 人力资 源减少和生产效率下降带来的破产风险能够带来 企业危机管理意识的觉醒。

突发大规模疫情不仅对人员造成重大伤亡，对 常态化运转的社会稳定冲击也不可忽视。近十几年 里, 对各个公共卫生事件对于经济影响的分析研究 发现, 这一类影响主要来源于其不确定性和突发性, 因此造成的冲击通常是短期的 (张连成等, $2003^{[3]}$; 鲁政委, $2009^{[4]}$; 胡鞍钢, $2003^{[5]}$ ), 但在长远角度 来看, 大规模疫情对经济发展会产生持续数十年的 结构性影响 (Lee 等, $2004^{[6]}$ )。尽管影响周期短, 不同行业呈现的发展情况依然有较大不同, 遭受较 大损失的主要是交通、旅游及餐饮业（鲁政委, $2009^{[4]}$; 戴特奇, $2011^{[7]}$; Joo Heesoo 等, $2015^{[8]}$ ), 但对于医疗消费品及医药行业有着一定的促进力 度 (Samantha 等, $2012^{[9]}$; 南方经济, $2003^{[10]}$; 杨 翠红, $\left.2003^{[11]}\right)$, 实际上, 大规模疫情对于经济的影 响程度和政府干预措施的效率以及强度有很大关 系 (Marcus 等, 2008 ${ }^{[12]}$ )，不同强度的控制政策的 经济成本是不一致的。这些直接冲击从行业消费、 贸易信息中反映, 并通过产业链进一步扩散到上下 游部门，从而影响整个社会经济系统的正常运行 (张一等, $2003^{[13]}$ )。

对于这种经济系统的影响研究在危机中和危 机后是学术界研究的热点, 但在研究效应的深入程 度和技术方面还有待改进，尤其是对于该类事件后 的产业联动影响研究几乎是空白。因此, 本文试图 通过新冠疫情风险冲击的产业响应机理分析, 揭示 大规模疫情的产业冲击效应, 期望为推动建立与超 大城市相匹配的居民广泛参与的社会应急管理与 快速响应机制, 减轻突发疫情对整体经济社会的影 响, 提升经济社会发展质量与人民生活水平提供决 策参考。
超大城市规模与不完善的应急管理体制不匹 配, 使得隔离措施下三大产业大部分停工, 因此, 疫情的发生使得短期内城市经济系统受到的负面 冲击更大, 经济基本面变差。另一部分与生活相关 的服务却超负荷运转, 促使资源流向生活、医疗生 产部门, 刺激新产业出现, 引发产业结构替代升级, 所以城市的经济系统在长久状态下始终能保持稳 定。

\section{3. 疫情风险冲击的产业响应机理分析}

\section{1 分析假设}

假设 1：存在产业自然市场行为的应激反应。 短期疫情导致各产业出现此消彼长的应激性调整。

假设 2: 经济社会系统存在制度创新需要。政 府应急逆向调控的必要与有效性。短期需要政府逆 向干预调整, 短期达到应急, 长期实现扶持新产业 出现, 加快产业结构替代升级, 缩短疫情导致各产 业发展失衡需要自然恢复的周期。

\section{2 疫情风险冲击的产业响应逻辑示意模型 分析}

经济社会处于不断的发展过程中, 要正常的运 转需要资本、劳动力、资源等基本要素的流通，扩 大经济要素的流通深度是市场经济不断发展的表 现形式之一。隔离不会影响到要素的存量, 但阻碍 了经济要素的自由高效流通。从微观层面上表现为 供求关系的改变 (参见图 1 )。人们对于某些特定商 品的需求对旅游等商品需求降低, 但政府干预维持 价格在短期不变, 导致市场均衡点的产量 Q下降, 宏观上表现为市场规模萎缩。对于生活必需品这一 类商品而言, 供求关系的改变是恰好相反的 (如虚 线所示), 此时要素的稀缺使得市场经济的自我调 节功能与政策强制干预之间的激烈冲突。

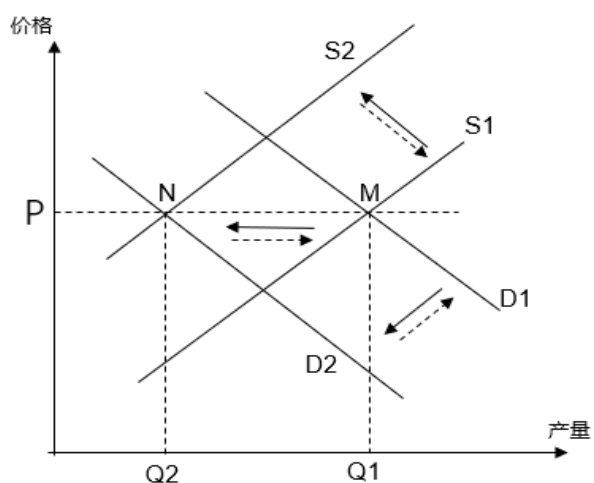

图 1 隔离经济下的供需关系 


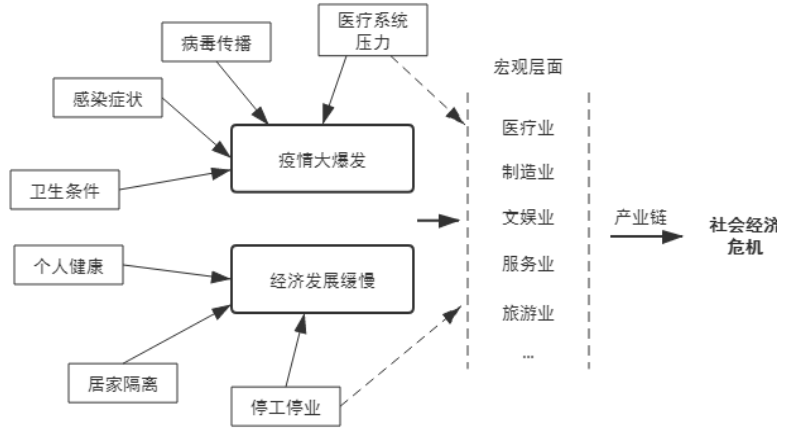

图 2: 疫情的经济影响演化机理

此次疫情所引发的社会危机，是处在病毒风险 暴露下的各个微观个体遭受到生命健康的威胁, 采 取隔离措施使得各行各业停工停产, 经济发展几乎 停滞; 其次, 病毒的不断传播与变异, 个体防护措 施不足与与日俱增的感染者给公共卫生系统造成 巨大压力, 推动疫情蔓延直至大爆发 (如图 2 所示); 由于各个行业和部门之间是紧密相连的, 某一行业 的影响会沿着产业链逐步向上下游产业扩散，上述 的单一供求关系改变会汇聚成对总供给关系的冲 击, 从而对整个系统的经济运行产生影响。这种链 式传导与扩散效应会使得疫情对经济的影响变得 更为复杂化, 某一行业的紧缩在错综复杂的产业联 系中被不断放大，产生的影响就更为深远。

\section{3 疫情风险的序贯性链式结构分析}

基于 “一一早期感染一一人群聚集一一传染 病风险高一一感染暴发一一公众恐慌——医疗系 统压力一一停工停业一一经济活动扰乱一一社会 失衡——”的序贯性链式风险生成机制及其演化 路径的系统特征, 分析中国新冠肺炎疫情经济社 会风险演化机理。

此次疫情爆发正值春节前夕，超大城市内务工 人口纷纷向外流动, 整个社会对烈性传染病的抵御 能力大大降低, 呈现出承灾主体的易感脆弱性。由 于社会整体的防疫意识淡薄, 对病情不够重视, 导 致前期疫情在湖北省内迅速爆发，并随着人口流动 扩散至全国各省, 甚至其他国家和地区。通过隔离 以达到疫情防控的目的，人力资源的限制使得企业 停工、社会停摆, 首先带来旅游业、餐饮业、交通 运输业的巨大经济损失, 随后冲击到供应端, 生产 要素流动的不均匀影响工厂生产、农业种植, 导致 整个经济系统失衡, 从而引发社会失衡。

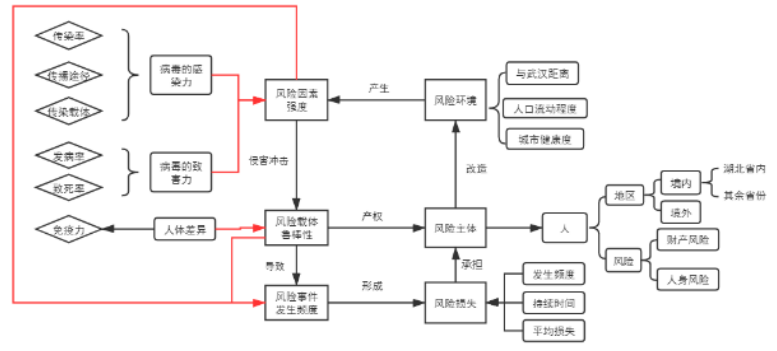

图 3: 疫情风险六要素分析

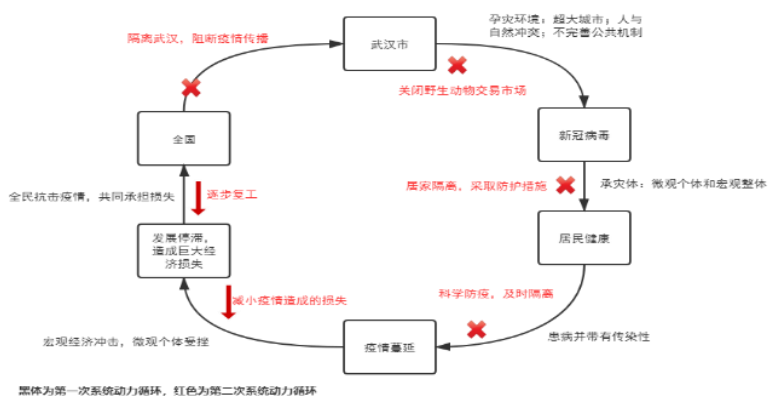

图 4: 疫情风险要素冲击动力学模型

\section{4. 疫情风险冲击的产业响应的灰色预测模 型分析}

\section{1 构建疫情风险冲击的产业响应的灰色预 测模型}

针对受疫情影响产业, 以实际月度行业经营指 标反映受到疫情的影响结果, 设 $X^{(0)}=$ $\left(x_{1}^{(0)}, x_{2}^{(0)}, x_{3}^{(0)}, \ldots x_{12}^{(0)}\right)$ 为原始时间序列, 级比 $\sigma^{(0)}(k)=\frac{x^{(0)}(k-1)}{x^{(0)}(k)}, k \geq 2$, 如果上述各个行业月度 指标都使得级比 $\sigma^{(0)}(k) \in(a, b)$, 则上述时间序列 $X^{(0)}$ 符合建立 GM $(1,1)$ 灰色预测模型的条件。

（1）取出一个临界值 $\xi(\xi=\mu)$, 低于行业月 平均收入 $\mu$ 则视为异常, 那么可以得到一列异常值 的时间序列: $X_{\xi}$

（2）根据对应关系: 作映射: $M_{\xi}: X_{\xi} \rightarrow t_{\xi}$, 那 么可以得到:

$t_{\xi}^{(0)}$

$=\left(t_{\xi 1}{ }^{(0)}, t_{\xi 2}{ }^{(0)}, t_{\xi 3}{ }^{(0)}, t_{\xi 4}{ }^{(0)}, t_{\xi 5}{ }^{(0)}, t_{\xi 6}{ }^{(0)}, t_{\xi 7}{ }^{(0)}, t_{\xi 8}{ }^{(0)}, t_{\xi 9}{ }^{(0)}, t_{\xi 10}{ }^{(0)}\right)$

(3) 计算确定一次累加时间序列和紧邻均值 时间序列: 根据 $t_{\xi k}{ }^{(1)}=\sum_{i=1}^{k} t_{\xi i}^{(0)}$

则有: $t_{\xi k}{ }^{(1)}=\left(t_{\xi 1}{ }^{(1)}, t_{\xi 2}{ }^{(1)}, \ldots, t_{\xi 10}{ }^{(1)}\right)$

由 $t_{\xi i}{ }^{(1)}$ 的紧邻均值生成时间序列为: $Z^{(1)}=$ $\left(z_{2}{ }^{(1)}, z_{3}{ }^{(1)}, \ldots, z_{10}{ }^{(1)}\right)$, 其中 $z_{i}^{(1)}=\frac{1}{2}\left(t_{\xi i-1}^{(1)}+t_{\xi i}^{(1)}\right)$

（4）构造数据矩阵 B 和数据向量 $\mathrm{Y}$ :

Y $=\left[t_{\xi 2}{ }^{(0)}, t_{\xi 3}{ }^{(0)}, t_{\xi 4}{ }^{(0)}, t_{\xi 5}{ }^{(0)}, t_{\xi 6}{ }^{(0)}, t_{\xi 7}{ }^{(0)}, t_{\xi 8}{ }^{(0)}, t_{\xi 9}{ }^{(0)}, t_{\xi 10}{ }^{(0)}\right]^{T}$

(5) 运用 MATLAB 数学软件进行矩阵运算, 计 算发展系数 $m$ 和灰作用量 $n$;

$$
\hat{a}=\left[\begin{array}{c}
m \\
n
\end{array}\right]=\left(B^{T} B\right)^{-1} B^{T} Y
$$

（6）计算出 GM $(1,1)$ 灰色预测模型:

$$
\hat{x}^{(1)}(k+1)=\left(x^{(0)}(1)-\frac{n}{m}\right) e^{-m k}+\frac{n}{m}
$$

（7）进行预测精度检验：

$\hat{x}^{(0)}(k+1)=\hat{x}^{(1)}(k+1)-\hat{x}^{(1)}(k)$, 得到异常 点的预测误差

（8）运用 GM $(1,1)$ 模型进行预测

\section{模型中符号说明:}

$x_{i}^{(0)}$ : 序号为 $i$ 对应行业月收入或指标; $i$ $=1,2, \cdots, \mathrm{k}$

$X_{\xi}$ ：异常数据组成的集合; 
$t_{\xi}^{(0)}$ : 异常点对应的序号集;

$t_{\xi k}{ }^{(0)}$ : 第 $\mathrm{k}$ 个异常点对应的序号

$t_{\xi k}{ }^{(1)}$ : 一次累加时间序列

$Z^{(1)}$ : 紧邻均值生成时间序列

\section{2 疫情风险冲击的产业响应的统计性描述}

本文数据全部来源于国家统计局、文化和旅游
部、交通运输部及中经网统计中心。由于疫情发生 在春节期间, 各行业数据有明显的季节性, 为了统 一口径和衡量标准, 本文选取了 2015 年-2019 年农 牧渔业季度产值、工业季度产值、春运 40 日客运 量、餐饮业 1-2 月收入、旅游业半年度国内旅游业 收入以及文娱业居民平均支出 (如表 1 所示), 六个 时间序列经检验均符合建立 GM $(1,1)$ 的条件, 对各 序列分别进行灰色预测。

表 1 各主要产业的影响变动情况

\begin{tabular}{ll}
\hline \multicolumn{1}{c}{ 行业 } & \multicolumn{1}{c}{ 影响变化情况 } \\
\hline 农、林、牧、渔业 & 短期滞销, 人力资源缺口导致长期供给短缺, 价格上升。 \\
工业 & 但疫情相关制造企业爆发式增长, 但大面积停工使得总产值短期内大幅度下滑 \\
交通运输业 & 客运量大幅下降, 春运期间载客量不足四成。 \\
餐饮业 & 超七成店铺停工无任何营收, 仅少量必需外卖店铺为医疗人员提供餐饮服务。 \\
旅游业 & 疫情期间旅游业基本停工, 产业收入下跌近 94\%。 \\
教育和文娱业 & 影院、学校停工停学, 但催生线上教育和娱乐产业迅速增长。 \\
\hline
\end{tabular}

表 2 2015-2019 年各主要产业经营情况

\begin{tabular}{|c|c|c|c|c|c|c|}
\hline 指标 & $\begin{array}{c}\text { 农、林、牧、渔 } \\
\text { 业 }\end{array}$ & 工业 & 交通运输业 & 餐饮业 & 旅游业 & 教育和文娱业 \\
\hline 单位 & 亿 & 亿 & 万人 & 亿 & 万亿 & 元/人 \\
\hline 2015 & 7686.8 & 53471.1 & 28.09 & 5079.06 & 1.65 & 330.37 \\
\hline 2016 & 8665.5 & 53666.4 & 29.1 & 5651.2 & 1.88 & 423.23 \\
\hline 2017 & 8595.8 & 60909.3 & 29.78 & 6251.3 & 2. 17 & 480 \\
\hline 2018 & 9005.8 & 66905.6 & 29.7 & 6612.9 & 2.45 & 454 \\
\hline 2019 & 9249.4 & 71064.5 & 29.8 & 7251.1 & 2.78 & 547.85 \\
\hline
\end{tabular}

\section{3 预测修正模拟分析}

使用 AGO 生成一次累加时间序列后, 通过 (2)、(3) 做映射后生成紧邻值时间序列, 在 MATLAB 中进行 矩阵计算 (5) 得到发展系数 $m$ 和灰作用量 $n$, 代入 (6) 中得到分析结果并进行误差检验和关联度检验, 此时设置分辨系数 $p=0.5$ 。对六个行业的原始时间序列做重复操作, 得到以下预测结果:

表 3 GM $(1,1)$ 模型估计和检验结果

\begin{tabular}{|c|c|c|c|c|c|c|}
\hline \multicolumn{7}{|c|}{ 农、牧、林、渔业（亿） } \\
\hline $\mathrm{X}^{(0)}$ & 7686.8 & 8665.5 & 8595.8 & 9005.8 & 9249.4 & \\
\hline$\hat{x}^{(1)}(k+1)$ & 7686.8 & 8554.8 & 8767.2 & 8984.73 & 9207.7 & $* 9436.2$ \\
\hline 绝对误差 & - & 0 & 0.0329 & 0.0109 & 0.0089 & \\
\hline 相对误差 & - & $-1.2770 \%$ & $1.9935 \%$ & $-0.2339 \%$ & $-0.4507 \%$ & $\xi$ \\
\hline 关联度 & - & 1 & 0.3333 & 0.5994 & 0.6478 & 0.6451 \\
\hline \multicolumn{7}{|c|}{ 工业（亿） } \\
\hline $\mathrm{X}^{(0)}$ & 53471.1 & 53666.4 & 60909.3 & 66905.6 & 71064.5 & \\
\hline$\hat{x}^{(1)}(k+1)$ & 53471.1 & 54750.1 & 59973.1 & 65694.3 & 71961.4 & *78826. 32 \\
\hline 绝对误差 & - & 0 & 0.0396 & 0.0468 & 0.0098 & \\
\hline 相对误差 & - & $2.0192 \%$ & $-1.5371 \%$ & $-1.8104 \%$ & 1. $2621 \%$ & $\xi$ \\
\hline 关联度 & - & 1 & 0.3716 & 0.3333 & 0.7042 & 0.6023 \\
\hline \multicolumn{7}{|c|}{ 交通运输业（亿人次） } \\
\hline $\mathrm{X}^{(0)}$ & 28.09 & 29.1 & 29.78 & 29.7 & 29.5 & \\
\hline$\hat{x}^{(1)}(k+1)$ & 28.09 & 29.29 & 29.49 & 29.69 & 29.89 & $* 30.1$ \\
\hline 绝对误差 & - & 0 & 0.0165 & 0.0069 & 0.0034 & \\
\hline 相对误差 & - & $0.6659 \%$ & $-0.9617 \%$ & $-0.0175 \%$ & $0.0327 \%$ & $\xi$ \\
\hline 关联度 & - & 1 & 0.3333 & 0.5442 & 0.7057 & 0.6458 \\
\hline
\end{tabular}




\begin{tabular}{|c|c|c|c|c|c|c|}
\hline \multicolumn{7}{|c|}{ 餐饮业（亿） } \\
\hline$X^{(0)}$ & 5079.06 & 5651.2 & 6251.3 & 6612.9 & 7251.1 & \\
\hline$\hat{x}^{(\mathbf{1})}(k+1)$ & 5079.06 & 5685.78 & 6160.11 & 6674.01 & 7230.78 & $* 7834$ \\
\hline 绝对误差 & - & 0 & 0.0228 & 0.0036 & 0.0114 & \\
\hline 相对误差 & - & $0.6120 \%$ & $-1.4587 \%$ & $0.9241 \%$ & $-0.2802 \%$ & $\xi$ \\
\hline 关联度 & - & 1 & 0.3333 & 0.7582 & 0.5001 & 0.6479 \\
\hline \multicolumn{7}{|c|}{ 旅游业（万亿） } \\
\hline$X^{(0)}$ & 1.65 & 1.88 & 2.17 & 2. 45 & 2.78 & \\
\hline$\hat{x}^{(1)}(k+1)$ & 1.65 & 2.37 & 2.50 & 2.64 & 2.79 & $* 3.16$ \\
\hline 绝对误差 & - & 0 & 0.0172 & 0.0102 & 0.0085 & \\
\hline 相对误差 & - & $0.5627 \%$ & $-0.9325 \%$ & $-0.2252 \%$ & $-0.0142 \%$ & $\xi$ \\
\hline 关联度 & - & 1 & 0.3333 & 0.4567 & 0.5028 & 0.5732 \\
\hline \multicolumn{7}{|c|}{ 教育和文化娱乐（元/人） } \\
\hline $\mathrm{X}^{(0)}$ & 330.37 & 423.23 & 480 & 454 & 547.85 & \\
\hline$\hat{x}^{(1)}(k+1)$ & 330.37 & 424. 41 & 457.07 & 492.25 & 530.14 & $* 570.94$ \\
\hline 绝对误差 & - & 0 & 0.0572 & 0.0872 & 0.0453 & \\
\hline 相对误差 & - & $0.0277 \%$ & $-4.77771 \%$ & $8.4249 \%$ & -3.2335 & $\xi$ \\
\hline 关联度 & - & 1 & 0.4325 & 0.3333 & 0.4902 & 0.5640 \\
\hline
\end{tabular}

注: “*” 为灰色预测正常值

对灰色预测结果进行残差分析后相对误差较 小, 预测精度较高, 三次关联度检验的 $\xi$ 值均大于 $\mathrm{p}$, 因此关联度好, 符合条件。对 2020 年的中国各产业 经济运行状况进行分析后认为, 在无疫情影响的情 况下, 中国第一季度农业及相关产值应为 9436 亿, 工业产值约 7.8 万亿, 据国家统计局初步核算, 中 国第一季度第一产业增加值 10186 亿元，同比下降 3. 2\%; 第二产业增加值 73638 亿元，下降 9.6\%，第 三产业增加值 122680 亿元, 下降 5.2\%, 基本符合 预测和分析。而中国上半年旅游业收入预计为 2.8 万亿, 疫情期间 1-2 月由于景区停业等影响, 综合 对比 2003 年非典受影响情况, 认为旅游业收入下 降预计约 93\%; 而 2020 年春运 40 日正常值应在 30 亿人次, 实际值为 14.8 亿人次, 客运量下降超 $50 \%$; 1-2 月期间餐饮业收入正常为 7834 亿人民币, 据不 完全统计超七成企业该短时间无营收, 损失达 4211 亿元。通过事件分析法对疫情带来的不确定性影响 进行预测后，认为短期 (1-2 月) 交运业、旅游业 和餐饮业预计损失高达 1.38 万亿; 相反线上教育 和文化娱乐行业异军突起, 预计将实现超额增长, 六个产业长期综合对经济造成约 1\%的影响。

\section{5. 研究结论与启示}

结合实证检验与对比分析结果发现, 受到影响 仍然是最为严重行业为餐饮、酒店、交通与出行直 接挂钩的产业, 并且对于餐饮、交运、旅游等行业 及产业链相关的冲击是不容乐观的。同掌握国民经 济命脉的制造业不同，这类行业公司数量里中小规 模企业占大多数, 没有足够完备的应急风险管理措 施, 在停业时间中面临现金流风险, 为了维持经营, 企业不得不做出裁员、关店等举措使得服务业人力 资源需求削减, 在就业环境愈发激烈的环境下进一 步加大了就业压力。同时, 疫情也催生了对医药、
医疗器械、卫生服务等产业爆炸式需求, 短时间内 生产资源迅速流向医疗卫生行业, 并带动了下级关 联产业链的活力, 为未来医疗卫生行业的改革发展 打下了基础; 另外, 隔离所催生的新生活和办公方 式为线上文化娱乐与教育行业带来新的发展机遇 和盈利模式, 同时掀起智能产业的新一轮革命。

当然, 从长远来看, 由于服务业与工业出现此 消彼长的结构性应激性变化调整, 以信息产业和人 工智能等高技术为代表的新兴产业的迅猛发展, 加 快化对传统劳动密集型产业的替代, 将推动产业结 构优化升级周期, 有望提前进入新的高技术新产业 周期。通过向市场注入流动性、针对性税收减免、 社会性保费减免等措施能够有效地帮助微观个体 度过生存难关。配合流动性宽松政策帮助股市发挥 直接融资的作用, 将资金引流到资本市场上帮助实 体经济填补缺口, 实现金融业对于实体经济的协同 发展, 尽快推动经济沿常态轨道运行。

此外, “全民健康” 是国家富强的重要标志, 也 是实现全面小康的必要前提。从中国当前的公共卫 生应急能力和快速响应程度来看, 暴露了检疫不合 格、预警不及时、反应不灵敏的问题, 在全面建成 小康社会的决胜时期, 要重视对健康城市理念的认 知程度, 强化居民公共卫生防疫意识, 推动建立与 超大城市相匹配的居民广泛参与的社会应急管理 与快速响应机制。让健康概念深入城市的管理工作 中, 实现真正的全民健康, 为人力资本质量的提升 打好基础。

致谢: 本文是北京高校高精尖学科 “战略经济与军 民融合” 交叉学科（GJJ2019163）、中央财经大学“一 流学科” 建设项目 “巨灾风险管理与自然灾害治理 现代化研究”, 2020 年度国家民委民族研究项目 “后 脱贫时代西部藏区乡村振兴风险与内置金融研究 (2020-GMB-030)”的阶段性研究成果。 


\section{参考文献}

[1] 吕炜. 后 SARS 时期: 经济影响与政策取向 $[\mathrm{J}]$. 财经 问题研究，2003 (09) : 22-27.

[2]张文斗, 祖正虎, 许晴, 徐致靖, 刘巾杰, 郑涛. 突发大 规模疫情对经济的影响分析 [J]. 军事医 学, 2014, 38(02) : 124-128.

[3]张连城, 贾金思. 市场失灵与政府作为—— “非典” 疫情对中国经济冲击的性质和原因分析 [J]. 经济与管理 研究, 2003 (05) :67-71.

[4]鲁政委. 从 SARS 看 H1N1 的市场影响 $[J]$. 现代商业银 行, 2009 (12) : 19-21.

[5]胡鞍钢. SARS 危机对我国经济发展的影响分析 [J]. 管 理评论, $2003(04): 3-5+63$.

[6]Lee JW, Mc Kibbin WJ. Estimanting the global economic costs of sars [C]. Washington DC: Paper presented at the Learning from SARS: Preparing for the Next Disease Outbreak - Workshop Summary, 2004. [7] 戴特奇. 非典事件对民航客运的干预影响分析 [J].中 国民航大学学报, 2011,29(02):47-51.

[8] Joo Heesoo, Henry Ronald E, Lee YeonKyeng, Berro Andre D, Maskery Brian A. The effects of past SARS experience and proximity on declines in numbers of travelers to the Republic of Korea during the 2015 MERS outbreak: A retrospective study. [J]. Travel medicine and infectious disease, 2019, 30.

[9] Samantha M. Tracht, Sara Y. Del Valle, Brian K. Edwards. Economic analysis of the use of facemasks durig pandemic (H1N1) 2009[J]. Journal of Theoretical Biology, 2012, 300.

[10]本刊编辑部. “非典”对中国经济影响到底有多大 一经济学家谈 “非典” 对中国经济的影响 [J]. 北方经 济, 2003(06) : 19-22.

[11]杨翠红, 陈锡康. SARS 对我国消费的影响程度分析 [J]. 管理评论, $2003(04): 13-17+63$.

[12] Marcus Richard Keogh-Brown, Richard David Smith. The economic impact of SARS: How does the reality match the predictions?[J]. Health policy, 2008, 88 (1).

[13]张一, 吴莹, 汪寿阳, 徐山鹰. SARS 对中国进出口贸易 的影响分析 [J]. 管理评论, 2003(04): 23-27+63. 